\title{
Surgimento e consolidação da Documentação: subsídios para compreensão da história da Ciência da Informação no Brasil
}

\section{Cristina Dotta Ortega}

\author{
Doutora em Ciência da Informação pela Escola de \\ Comunicações e Artes (ECA/USP). Professora \\ Adjunta da Escola de Ciência da Informação \\ (ECI/UFMG)
}

As denominações Biblioteconomia, Documentação e Ciência da Informação marcam presença no Brasil, mas a segunda configura-se como a menos conhecida. Deste modo, o artigo apresenta mapeamento do surgimento e consolidação da Documentação, com o objetivo de fornecer subsídios para compreensão da influência deste movimento no Brasil. Realiza revisão bibliográfica a partir de obras que apresentam a concepção e o desenvolvimento da Documentação e dados históricos da área no Brasil. Conclui que a influência da Documentação europeia no Brasil do final do século XIX aos anos 1930 foi pontual mas efetiva, enquanto a influência da Documentação ocorrida entre os anos 1950 e 1960 relacionou-se mais fortemente à produção em curso nos Estados Unidos. A pesquisa evidencia a forte herança da Documentação na França, Espanha e Portugal e a validade deste movimento para a superação das abordagens restritivas atribuídas à Biblioteconomia e dos contínuos embates sobre o objeto da Ciência da Informação.

Palavras-chave: História da documentação; História da ciência da informação no Brasil

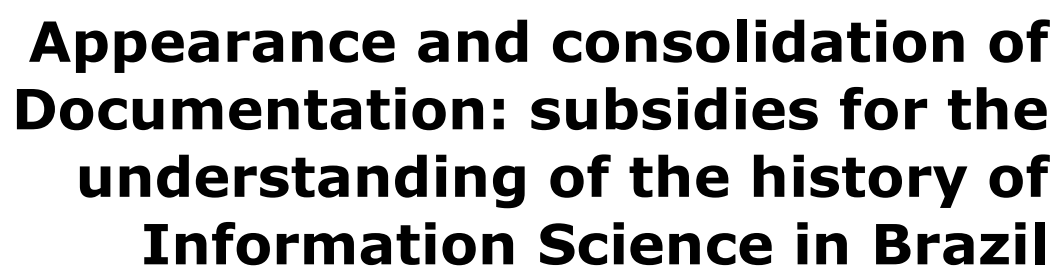


The terms Librarianship (Biblioteconomia), Documentation, and Information Science are widely used in Brazil. However, the second is the less known. Thereby, the article presents a mapping of the appearance and consolidation of Documentation, aiming to provide subsidies for the understanding of the influence of this movement in Brazil. It presents a bibliographical revision starting from works which present the conception and the development of Documentation, and historical data of the field in Brazil. It concludes that the European influence in Brazil from the end of the XIX century to the 1930s was brief, although effective, whilst the influence of Documentation, which occurred between 1950 and 1960, was strongly related to the production that was taking place in the United States. The research evidences the strong inheritance of Documentation in France, Spain and Portugal, and the importance of this movement to the overcoming of the restrictive approaches attributed to Librarianship, and the continuous clashes over the object of Information Science.

Keywords: History of the documentation; History of information science in Brazil

\section{Introdução}

A Ciência da Informação relaciona-se a práticas profissionais que foram elaboradas academicamente em momento posterior. Suas diversas correntes ainda não foram abordadas a partir de reflexões que as englobem e confrontem suficientemente. Por este motivo, a pesquisa em Ciência da Informação apresenta avanços mas baixa consolidação.

Dentre estes avanços, temos a Documentação ${ }^{1}$, corrente teórica e prática profícua proposta no final do século XIX e crescentemente considerada como uma das origens da Ciência da Informação. Esta corrente é composta por princípios e técnicas que promoveram o foco na representação do conteúdo dos diversos documentos visando a ações de promoção do uso da informação. A ênfase no reconhecimento da Documentação é pertinente pois sua fundação e consolidação na Europa, observável na literatura e nas práticas profissionais, indica a existência de objeto construído de modo consistente e deflagra abordagem de informação que é específica da área.

O surgimento da linha predominante estadunidense de Ciência da Informação na metade do século $X X$ conduziu 0 interesse de pesquisadores para uma abordagem sobre informação, de tal modo

\footnotetext{
${ }^{1}$ Em geral, a forma 'documentação' é usada para indicar o conjunto de técnicas de organização da informação visando recuperação, acesso e uso, e a forma 'Documentação' para referir-se à área que estuda os fundamentos e métodos relacionados a estas técnicas.
} 
ampla, que acabou por gerar indefinição e ambiguidade. Quanto à relação controversa entre Biblioteconomia e Documentação, entendemos que esta contribui fortemente para a abrangência e generalização daquela para além da noção de gestão de acervos, como busca expressar o termo Biblioteconomia e Documentação. Os termos Biblioteconomia, Documentação e Ciência da Informação representam a área, porém se manifestam a partir de significados distintos, uma vez que ocorreram em diversos tempos e espaços de constituição, sedimentação e transformação, como tratamos em Ortega (2004).

Considerando que as três denominações - Biblioteconomia, Documentação e Ciência da Informação - marcam presença no Brasil, este artigo trata da segunda por sua relevância, mas também por configurar-se como a menos conhecida no país. Deste modo, realizamos mapeamento sobre o surgimento e consolidação da Documentação, com o objetivo de obter subsídios para compreensão da influência deste movimento no Brasil. Embora fosse necessário articular esta análise aos momentos sócio-políticos, econômicos e culturais brasileiros em que este movimento ocorreu, o baixo conhecimento nacional sobre o mesmo demanda exploração sobre as origens e trajetórias que permitem caracterizá-lo.

Partimos da hipótese de que esta compreensão é dependente de três fenômenos emblemáticos da história da Ciência da Informação no Brasil: a Documentação fundada e ainda presente na Europa; a controvérsia entre Biblioteconomia e Documentação; e a passagem da Documentação e o surgimento da Ciência da Informação nos Estados Unidos.

Como metodologia, realizamos revisão bibliográfica sobre a história da área e análise comparativa entre os eventos citados e os conceitos que os sustentam, com apoio teórico em obras que apresentam a concepção e o desenvolvimento da Documentação e dados históricos da área no Brasil. A maior parte destes fatos é apresentada de forma cronológica por entendermos que este procedimento facilita a ordenação do pensamento a partir dos diversos conceitos que foram, histórica e geograficamente, propostos, sobrepostos e contrapostos.

\section{A concepção otletiana fundadora da Documentação}

Os advogados Paul Otlet (1868-1944) e Henri La Fontaine (18541943) foram os mentores do Instituto Internacional de Bibliografia (IIB) ${ }^{2}$, criado em 1895 na Bélgica, e do Repertório Bibliográfico Universal (RBU), cujo projeto foi proposto no mesmo ano e chegou a ter 16 milhões de fichas em 1934. O sonho de Otlet era o de oferecer um índice de assuntos por meio do RBU que permitiria ir (por assunto) ao coração do conhecimento (FAYET-SCRIBE, 2001, p. 47 e 49). Este sonho relacionava-

\footnotetext{
2 O IIB teve seu nome alterado para Instituto Internacional de Documentação (IID) em 1931, e para Federação Internacional de Documentação (FID) em 1937. A partir de 1986, recebeu a denominação Federação Internacional de Informação e Documentação, mantendo a sigla original. A FID foi dissolvida em 2002. (Disponível em: http://people.ischool.berkeley.edu/ buckland/fidhist.html. Acesso em: 22 ago. 2009).
} 
se à ideia de que o acesso ao conhecimento por todos os povos levaria a uma maior compreensão da concepção de alteridade, no sentido do conhecimento das diferenças, o que possibilitaria a paz mundial.

Segundo Fayet-Scribe (2001, p. 77), para a elaboração do RBU foram definidas normas para registros bibliográficos, registros catalográficos internacionais, formatos dos documentos (em particular, a ficha) e empregados tipos específicos de mobiliário. As normas catalográficas redigidas por Charles Sustrac e o formato da ficha de 7,5 por $12 \mathrm{~cm}$ foram inspirados nas normas anglo-saxãs. A Classificação Decimal de Dewey (CDD), publicada em 1876 nos Estados Unidos, foi utilizada inicialmente em sua $5^{a}$ edição (de 1894) para o trabalho de classificação dos documentos do RBU. A classificação decimal foi editada pela primeira vez em francês em 1905, mais tarde sendo revista e conduzindo a um novo instrumento documentário, a Classificação Decimal Universal (CDU), que é extensamente utilizada na Europa até os dias de hoje.

Otlet adotou a palavra documentação inicialmente em 1903, em artigo intitulado Les sciences bibliographiques et la documentation, no sentido do processo de fornecimento de documentos ou referências dos mesmos àqueles que precisam da informação que eles contêm. Este autor refere-se a um corpo de conhecimento denominado ciências bibliográficas definido como: produção, fabricação de material, distribuição, registro, estatística, conservação e utilização, por esta razão incluindo compilação, impressão, publicação, venda, bibliografia e biblioteconomia. Otlet considerou como documentos não somente livros e manuscritos, mas também arquivos, mapas, esquemas, ideogramas, diagramas, desenhos e reproduções dos mesmos, fotografias de objetos reais, entre outros (OTLET, 1903, citado por WOLEDGE, 1983, p. 270-271). Para FayetScribe (2001, p. 47, 49 e 50), este texto pode ser considerado o fundador da obra de Otlet. Segundo esta autora, a biblioteca deixa de ser apenas uma instituição conservadora de livros e estes não são mais os únicos em torno dos quais poderiam ser identificados conhecimentos: a ideia de documento é criada, importando sua função menos que sua morfologia.

Mais à frente, designando a atividade específica de coletar, processar, buscar e disseminar documentos, Otlet usou o termo documentação, em 1905, no artigo L'organisation rationelle de l'information et de la documentation en matière economique (OTLET, 1905, citado por CHERNYI ; GILYAREVSKII ; MIKHAILOV, 1973, p. 46). Observamos aí provavelmente o primeiro uso das palavras informação e documentação.

Entre 1905 e 1917, Otlet foi abandonando a palavra bibliografia em suas publicações em proveito das palavras documentação e informação, ainda que muitas vezes empregue uma pela outra. No Tratado de Documentação (citado a seguir), ele fez uso da palavra Documentologia para designar o campo do conhecimento que propõe ultrapassando as palavras bibliografia, bibliologia e documentação (FAYET-SCRIBE, 2001, p. 52). 
A concepção teórico-prática desta corrente foi sistematizada por Otlet no Tratado de Documentação, publicado em 1934. Em seu início consta a bandeira (ainda atual) da Documentação como a da necessidade de tornar acessível a quantidade de informação publicada, produzindo "um todo homogêneo destas massas incoerentes", para o que seriam necessários novos procedimentos, distintos da Biblioteconomia, conforme eram aplicados até aquele momento (OTLET, 1996, p. 6).

Três anos mais tarde, apresentando visão sistêmica desenvolvida pelos teóricos seguintes por meio da noção de fluxo documentário, Otlet descreve a Documentação como sendo constituída por uma série de operações distribuídas, hoje, entre pessoas e organismos diferentes. 0 autor, o copista, o impressor, o editor, o livreiro, o bibliotecário, o documentador, o bibliógrafo, o crítico, o analista, o compilador, o leitor, o pesquisador, o trabalhador intelectual. A Documentação acompanha o documento desde o instante em que ele surge da pena do autor até o momento em que impressiona o cérebro do leitor (OTLET, 1937).

No decorrer do tempo, muitas definições de Documentação surgiram. Wolegde (1983, p. 270) ressalta uma que considera clara e não ambígua, e semelhante àquela proposta por Otlet em 1903. Esta definição foi apresentada no periódico Journal of Documentation em sua primeira edição, em 1945, por seu editor, Theodore Besterman:

Qualquer coisa em que conhecimento é registrado é um documento, e documentação é todo processo que serve para tornar um documento disponível para alguém que busca conhecimento. Biblioteconomia e organização de serviços de informação, bibliografia e catalogação, resumo e indexação, classificação e arquivamento, métodos fotográficos e mecânicos de reprodução; todos eles e muitos outros são canais de documentação que guiam o conhecimento até quem o solicita.

\section{A consolidação da Documentação}

$\mathrm{Na}$ continuidade da perspectiva informacional proposta por Otlet, aqueles que nela atuaram viram-se obrigados a buscar possibilidades de interpretação para suas exposições reiteradas, difusas e prepotentes e para sua produção dita científica - como podemos observar no Tratado realizada de forma detalhista, descritiva e enciclopédica, menos que argumentativa, conforme relata Rayward (ARNAU RIVED; SAGREDO FERNÁNDEZ, 1993).

Talvez por estes motivos, o percurso de desenvolvimento da Documentação contou, simultaneamente, com contestadores e adeptos fervorosos. Em especial após a morte de Otlet, seus continuadores foram instados a compreender o momento político e cultural que caracterizou o início do século na Europa. Estudos sobre Documentação foram desenvolvidos por vários autores como Bradford (1951), Vickery (1959), Shera (1966, entre outros), Sagredo Fernández e Izquierdo Arroyo 
(1983), e outros. Ressaltamos ainda as pesquisas realizadas pelo grupo francês das Ciências da Informação e Comunicação e pelo espanhol López Yepes, que tratamos à frente.

Quanto às obras básicas sobre o tema, o livro de Suzanne Briet "Qu'est-ce que la documentation?", de 1951, foi traduzido para o espanhol em 1960, e apenas em 2006 para o inglês. André Cannone, na Bélgica, produziu uma edição fac-similar do Tratado de Documentação em 1989 e buscou retomar os trabalhos de Otlet. O Tratado recebeu versão espanhola em 1996, mas não possui versão em inglês. Apenas bem recentemente, estas duas obras foram disponibilizados em texto integral na Internet.

Rayward (1967, 1975, outros) tem publicado em idioma inglês sobre a obra de Otlet, buscando identificar os possíveis significados deste tema nos contextos atuais. Michael Buckland, ao lado de Rayward, é um dos responsáveis pela divulgação da Documentação neste idioma no contexto de seus estudos históricos sobre Ciência da Informação. Apesar da extensa e antiga produção de literatura sobre Documentação na Europa, as contribuições de Rayward e Buckland têm demonstrado grande potencial de difusão e influência. O aniversário de 100 anos da criação da FID foi um dos fatores que promoveu a divulgação das origens da Documentação.

Segundo Buckland (1996), os fundamentos e técnicas propostos por Otlet e sedimentados especialmente do final do século XIX aos anos 1930 receberam várias contribuições no seio da Europa até os dias atuais, mas muitas delas foram perdidas na devastação deste continente durante a Segunda Guerra Mundial. Apenas nos anos 1950 a Documentação surgiu com força nos Estados Unidos, dividindo espaço com a Biblioteconomia Especializada, e rapidamente sendo recolocada pela Ciência da Informação. Para Estivals (1978, p. 30, citado por LÓPEZ YEPES, 1995, p. 77), a obra de Otlet foi esquecida entre 1940 e 1965, década em que foi significativamente retomada na Europa.

Deste modo, encontramos na França, Espanha e Portugal, a referência inconteste sobre a continuidade teórica e prática dos princípios propostos por Otlet, em especial no tema da organização da informação e de aportes linguísticos e tecnológicos a este processo. Nestes países, a Documentação compõe a pesquisa, a formação e as práticas profissionais relacionadas. Tratamos a seguir das origens do termo nestes países.

\subsection{França}

Se o berço da Documentação é a Bélgica, sua normalização e organização deu-se efetivamente na França, no período de 1895 a 1937, como relata Fayet-Scribe (2001). Considerando o final do século XIX como um período de crescimento de produção de documentos, os métodos e instrumentos que permitiam recuperar a informação dos mesmos mostraram-se limitados. Para responder à necessidade de organizar, no nível coletivo, o conjunto de instrumentos de acesso à informação é que a 
Documentação se desenvolveu como um novo domínio de atividade. Segundo Fayet-Scribe, Otlet e o general Hippolyte Sebert (1839-1930), um dos fundadores do IIB e atuante do mesmo na França, desempenharam um papel importante na consolidação do setor da Documentação. A autora trata também da relação entre leitura pública e informação técnica e científica que, segundo entendemos, é fenômeno tão pouco enfrentado quanto emblemático para a compreensão da Ciência da Informação.

A história da Documentação conta, entre outras documentalistas francesas, com Suzanne Briet (1894-1989), funcionária da Biblioteca Nacional da França, discípula e continuadora de Otlet e autora de uma das obras clássicas da área, como citamos. Para ela, Otlet foi o líder internacional da Documentação, pois outros teriam sido menos ambiciosos, ou mais prudentes (BRIET, 1951, p. 9). Segundo os tradutores de sua obra para o inglês, Briet aborda a ciência e a cultura no contexto do desenvolvimento global do pós-guerra, entre a utopia de Otlet e a teoria da informação e a cibernética dos Estados Unidos. Afirmam que ela realiza caracterização de signo documentário em contextos institucionais e culturais que ainda é um desafio frente às abordagens quantitativas simples e positivistas daquele país (BRIET, 2006, p. v-ix). Buckland (1995) nomeia Briet como Madame Documentation, considerando-a pioneira da Ciência da Informação.

Para Briet, os termos special librarian, library e bibliography apresentavam outras acepções na França, onde os neologismos documentaliste, centre de documentation e documentographie foram considerados necessários para o momento por corresponderem a um estado, se não mais evoluído, ao menos doutrinariamente mais elaborado (BRIET, 1951, p. 40). Contudo, em viagem que realizou aos Estados Unidos, entre 1951 e 1952, Briet declarou que, dado o vigor do desenvolvimento dos serviços das bibliotecas especializadas neste país, os mesmos representariam os centros de documentação franceses, só que com outro nome. O secretário-geral da FID Donker Duyvis também realizou viagem aos Estados Unidos, em 1946, e fez afirmação semelhante quanto ao evidente 'espírito documentário' de bibliotecários e arquivistas deste país (MEYRIAT, 1993, p. 195). Para Duyvis, houve uma divisão entre bibliotecários e documentalistas na França, enquanto nos Estados Unidos, os bibliotecários passaram a exercer as funções da biblioteca pública e as da especializada.

De fato, o auge e o fim da Documentação, tal como proposto por Otlet e por diversos documentalistas da Europa, deu-se em 1937 durante o Congresso Mundial de Documentação Universal, realizado em Paris, na Exposição Internacional de Artes e Técnicas, como relata Fayet-Scribe (2001, p. 202-207). O Congresso conduziu à constatação de que a Documentação atingiu a maturidade em seus 40 anos em diversos aspectos como: padronização de sistemas de classificação, normalização da catalogação e da bibliografia, produção de instrumentos com as fontes do trabalho intelectual (anuários, repertórios, guias bibliográficos etc.), 
elaboração de terminologia da Documentação, adoção de novos suportes (como o microfilme) e reconhecimento de diversos tipos de informação especializada (como a cartográfica, a metereológica e a administrativa). O RBU, ainda que considerado uma excelente ideia, foi abandonado por representar um trabalho gigantesco e pouco realizável.

Segundo Fayet-Scribe, este evento e a própria Documentação caíram no esquecimento pois a proximidade da Segunda Guerra Mundial deflagrou um momento pouco propício para as utopias pacifistas em que se pautava a cooperação internacional necessária à elaboração de instrumentos de acesso ao conhecimento registrado. Ainda assim, o Congresso colocou em evidência a visão otletiana de uma economia intelectual em um espaço informacional internacional e significou o ato de nascimento da informação científica na sociedade.

Apenas por volta dos anos 1960, nova configuração científica se consolidou na França, como relata Couzinet (2004, p. 22-23). Neste período, pesquisadores preocupados com leitura, documentação, história do livro, mídias e cultura apresentavam dificuldade em encontrar reconhecimento em suas próprias disciplinas. Desta forma, Robert Escarpit, Jean Meyriat e Roland Barthes, entre outros, formaram o Comitê de Ciências da Informação e Comunicação (segundo tradução para o português adotada no texto original). Em 1975 o Comitê organizou sua primeira conferência sobre o tema das relações entre Ciências da Informação e Ciências da Comunicação e, em 1977, formou-se o Inforcom: Sociedade Francesa das Ciências da Informação e da Comunicação (SFSIC), a partir do qual, grupos de pesquisa e formações universitárias se constituíram.

Segundo Couzinet (2004, p. 25), as Ciências da Informação na França são uma vertente das Ciências Humanas e Sociais, cujo foco está centrado na construção e compartilhamento de conhecimentos em contextos sociais e culturais variados, contudo voltado para objetos que têm permanência no tempo e, como decorrência, para operações que realizem sua análise, produção e acessibilidade. Em função de sua origem, esta vertente inclui o estudo das mídias (jornais, rádio, televisão) e de estudos culturais (alguns aspectos relativos ao cinema, ao teatro, aos museus e à indústria cultural). Quanto ao termo Documentação, refere-se a um conjunto de métodos e técnicas; para abordar seus aspectos científicos e para fazer a diferenciação de outros aspectos das Ciências da Informação citados anteriormente, utiliza-se às vezes a expressão 'Ciências da Informação-Documentação'.

Couzinet, Régimbeau e Courbières (2001) afirmam que Buckland, Ray e outros pesquisadores de Ciência da Informação dos Estados Unidos conhecem os pioneiros europeus como Briet e Otlet, mas ignoram os trabalhos dos pesquisadores das Ciências da Informação e da Comunicação. Concordamos com Couzinet e colegas, uma vez considerarmos a produção deste grupo a principal referência em Documentação, além daquela de suas origens, e relevante contribuição à Ciência da Informação. Se apenas recentemente a concepção otletiana 
tem sido disseminada em idioma inglês, o trabalho destes pesquisadores franceses é pouco conhecido fora da Europa.

\subsection{Espanha}

A introdução e o desenvolvimento do conceito de Documentação na Espanha demonstram o papel significativo e particular que este país deflagra na história da Documentação, só comparado à França, cuja produção é sua referência básica.

Segundo López Yepes (1995, p. 256-258, 260, 262), o discurso Misión del bibliotecario lido por Ortega y Gasset na abertura do II Congresso de Bibliotecas e Bibliografia, em Madri, em 1935, apresentou um panorama de problemas gerais que se relacionavam com o movimento documentário otletiano, embora as palavras documentación e documentalista não aparecessem. Acredita ser possível que Ortega y Gasset tenha se influenciado pela obra de Otlet, publicada no ano anterior, e por seu colaborador Javier Lasso de la Vega que se iniciava no tema. López Yepes afirma que Lasso de la Vega é o espanhol que mais escreveu sobre o conceito de Documentação em obras publicadas entre 1947 e 1980, além de ter atuado na Espanha na implantação da CDU, na propagação do conceito de Documentação e na sua aplicação em campos do saber como o Direito. Consta na literatura, de modo recorrente, que a produção espanhola sobre o tema foi iniciada por Lasso de la Vega.

Contudo, produção científica e cursos deram-se efetivamente na Espanha a partir dos anos 1970 . É provável que a primeira obra históricoconceitual - por explorar as diversas correntes teóricas da área - seja o livro Teoría de la Documentación, publicado por López Yepes em 1978 e atualizado em 1995, com o título La Documentación como disciplina: teoría e historia. Assim como Lasso de la Vega, López Yepes entende os processos de documentação como condição necessária para a atividade científica e para o desenvolvimento da ciência.

A obra de López Yepes é identificada como aquela através da qual os professores (oriundos de outras áreas como Letras e Filosofia) das incipientes escolas espanholas de Biblioteconomia e Documentação conheceram e aprenderam o objeto e os limites internos e externos da disciplina (LÓPEZ-CÓZAR, 2002, p. 131). Observamos que, tanto Otlet quanto López Yepes são amplamente adotados na literatura produzida na Espanha, deflagrando o que podemos chamar de abordagem espanhola sobre Documentação.

Ainda que o termo Documentación seja o mais amplamente utilizado e reconhecido para denominar a pesquisa, o ensino e a prática profissional, a expressão Ciencias de la Documentación é usada desde os anos 1970 (LÓPEZ YEPES, 1978) e início dos anos 1980 (CURRÁs, 1982) no sentido do conjunto das disciplinas documentárias que estudam e executam os diversos aspectos do processo documentário (LÓPEZ YEPES, 1995, p. 321). Já o termo Ciencias de la Información é adotado neste país enquanto grande área composta pela Documentação e pelas disciplinas da 
Comunicação (como Jornalismo e Publicidade), supostamente por influência do movimento francês descrito anteriormente.

\subsection{Portugal}

Cursos de formação ocorreram de modo semelhante na França, Espanha e Portugal, inicialmente centrados no trabalho de conservação e arranjo em bibliotecas e arquivos.

Segundo Ribeiro (2005, p. 19 e 21-22), o Curso Superior de Bibliotecário-Arquivista, em Portugal, formou profissionais desde 1887 para o trabalho em bibliotecas e arquivos (predominantemente públicos) sob abordagem técnica e patrimonialista. Em 1982, o curso foi extinto e substituído pelo Curso de Especialização em Ciências Documentais, cuja palavra 'ciências' buscou significar a junção de várias disciplinas, supostamente mais científicas, e em consonância com os desafios técnicos e tecnológicos que estavam emergindo.

Para a autora, a designação Ciências Documentais não tem equivalência literal em outros idiomas europeus, mas aproxima-se do termo francês Documentation e do espanhol Ciencias de la Documentación. A designação foi substituída pelo termo Ciência da Informação em alguns espaços acadêmicos, mas na maioria das instituições portuguesas ainda prevalecem os tradicionais cursos de Ciências Documentais. A adoção do termo Ciência da Informação ocorreu na Universidade do Porto em 2001 para o curso de licenciatura, segundo o entendimento de que a palavra 'ciência' no singular possibilita a afirmação de uma área científica, com identidade e unidade do ponto de vista epistemológico que, englobando vários componentes aplicados, centra-se sobre o objeto de estudo e trabalho 'informação' no contexto de sistemas, serviços e ambientes orgânicos diversos e plurais. Ribeiro justifica ainda a recusa quanto à distinção conceitual entre Informação e Documentação, já que a segunda só pode existir como diferença específica da primeira e não como algo distinto e diverso.

\section{Outras correntes e a Documentação}

López Yepes (1995, p. 103, 106, 156) entende que o conceito otletiano foi se fragmentando em virtude da polêmica Biblioteconomia versus Documentação em suas diversas fases de justaposição, superposição, infraposição ou independência. Afirma que as abordagens documentalistas anglo-saxã, alemã e soviética que surgiram a partir dos anos 1950 e 1960 foram apoiadas por tratadistas continuadores da doutrina de Otlet e objetivaram a superação desta fragmentação para um conceito integrador de perspectiva informativa.

Observamos que movimentos de fragmentação e de superação da mesma ocorreram, mas a abordagem integradora esperada não se efetivou e ainda tomou novos contornos. Considerando que a corrente anglo-saxã (mais propriamente, estadunidense) foi a que permaneceu e que predomina, López Yepes apresenta seus desenvolvimentos iniciais e 
afirma sua relevância, mas não trata das implicações atuais da ampla disseminação desta corrente.

Tratamos a seguir da vertente documentalista das correntes denominadas Information Science (estadunidense), Information-und Dokumentationwissenschaft (alemã) e Informatika (soviética e de países do leste europeu).

\subsection{Corrente estadunidense}

A presença do termo Documentação nos Estados Unidos no nome de associações e cursos e na prática profissional e na literatura ocorreu, de fato, nos anos 1950. Hoje, este termo, além de ser pouco utilizado no país, não apresenta a abrangência do uso europeu, embora se aproxime do conceito de Ciência da Informação nele concebido e consolidado. Esta corrente, dentre as outras duas apresentadas à frente, é a que menos influências recebeu da Documentação de base otletiana.

A Special Libraries Association (SLA) foi criada em 1908, nos Estados Unidos, por John Cotton Dana, que utilizou pela primeira vez o termo Biblioteconomia Especializada, promovendo a separação do grupo constituído na American Library Association (ALA) (SHERA ; EGAN, 1961, p. 32).

Segundo William (1997, citado por SILVA ; RIBEIRO, 2002, p. 49), em 1937, Watson Davis criou o American Documentation Institute (ADI), grandemente influenciado pelas amplas práticas profissionais documentárias que observou dois anos antes na Europa ao participar do Congresso Internacional de Documentação. Silva e Ribeiro (2002, p. 49) afirmam que, na década de 1940, o ADI viveu uma fase de inatividade por falta de financiamento e de projetos, o que levou os membros da SLA (portanto, os bibliotecários especializados) a executarem o trabalho que competia àquela entidade. Segundo eles, isto evidencia claramente uma convergência de interesses e perfis. Ressaltamos, de outro modo, a precária significação local sobre Documentação frente ao projeto de institucionalização europeu.

Apenas por volta dos anos 1950, como decorrência do desenvolvimento tecnológico no contexto do pós-Segunda Guerra e com o crescimento exponencial da produção e uso de documentos, em especial os técnico-científicos, uma gama de profissionais esteve envolvida em atividades que caracterizaram efetivamente a presença da Documentação nos Estados Unidos. Este momento também foi marcado pelo rápido desenvolvimento dos sistemas automáticos de armazenamento e recuperação da informação, em especial os de recuperação por assuntos (WILLIAM, 1997, citado por SILVA ; RIBEIRO, 2002, p. 49-50).

Deste modo, houve um deslocamento semântico do termo Documentação nos Estados Unidos em dois sentidos. A Biblioteconomia Especializada proposta por Dana em 1908 dividiu espaço com a Documentação trazida da Europa durante seu auge nos anos 1930, o que se deu mais fortemente a partir dos anos 1950, período em que ocorreu 0 
auge deste movimento nos Estados Unidos. Neste período, a prática da Documentação foi realizada de modo a distinguir-se daquela da Biblioteconomia, a qual incluía a Biblioteconomia Especializada pois esta foi grandemente influenciada (e absorvida) pelo forte corporativismo da Biblioteconomia Geral ${ }^{3}$. Em seguida, a Documentação passou a ser representada pela área então chamada Information Retrieval ou Information Storage and Retrieval. A Information Retrieval - cuja tradução literal para o português não fornece o mesmo sentido - é entendida como o conjunto de estudos e atividades de armazenamento e recuperação da informação por meio de computadores, e se configura como umas das principais origens da Ciência da Informação nos Estados Unidos nos anos 1960.

\subsection{Corrente soviética}

Na União Soviética, surgiu no início dos anos 1960 corrente teórica e prática de extrema relevância por sua cobertura geográfica - sua obra básica "Fundamentos de la Informática" congrega referências a autores dos Estados Unidos, Europa e Europa Oriental - e por sua dimensão teórica, rigor e atualidade.

Os pesquisadores Chernyi, Gilyarevskii e Mikhailov (1973, p. 46-53, $55,57,71-73)$, responsáveis pela concepção desta corrente, investiram na busca de denominação alternativa ao termo Documentação, o qual não foi usado por ser considerado específico e polissemântico. Argumentam que um novo termo com um significado bem definido e único seria mais vantajoso que os termos velhos, os quais em geral, são utilizados em diferentes acepções, dificultando sua compreensão e influindo negativamente sobre o desenvolvimento da própria disciplina científica. Em busca de um termo mais amplo baseado no conceito de informação, afirmam que o termo substituto mais difundido seria Information Science. Contudo, entre os termos Informatologia (já adotado por alguns) ou Informática ('informação' mais 'automática'), optaram pelo último termo por conta da forma que vinha prevalecendo para denominar disciplinas científicas como cibernética, biônica, semiótica e cosmonáutica.

Segundo estes autores, o termo Informatika (como adotado em algumas fontes da literatura ocidental) refere-se à disciplina que estuda a estrutura e as propriedades (e não o conteúdo específico) da informação científica, assim como as leis que regem a atividade científico-informativa, sua teoria, história, metodologia e meios ótimos de apresentação (registro), coleta, processamento analítico-sintético, armazenamento, busca e disseminação da informação científica. Relaciona-se com a informação semântica, mas não se ocupa da avaliação qualitativa dessa informação, pois tal avaliação só pode ser realizada por especialistas em campos específicos da ciência ou da atividade prática.

\footnotetext{
${ }^{3}$ Segundo William (1997, citado por SILVA ; RIBEIRO, 2002, p. 50), na década de 1950, os documentalistas dos Estados Unidos buscaram distinguir-se dos bibliotecários, inclusive dos bibliotecários especializados: para este autor, neste período, os documentalistas tornaram-se idênticos aos bibliotecários especializados da fase inicial e estes se assemelharam aos bibliotecários generalistas.
} 
Quanto à relação desta corrente com a Biblioteconomia, os pesquisadores soviéticos apontam para uma distinção entre o serviço de informação científica e o serviço de orientação para a leitura, voltado à formação político-ideológico e cultural do povo soviético. Afirmam que a Biblioteconomia e a Bibliografia ainda adotariam alguns métodos da Informatika, mas o fundamental é que se entendesse a distinção entre suas tarefas básicas.

Traços da Documentação evidenciam-se nesta corrente quanto aos aspectos linguísticos dos métodos e instrumentos documentários, ao uso de tecnologia e ao foco na informação científica. Daí observamos que, apesar da criação de termo específico, o pensamento documentário permeia esta corrente. Para López Yepes (1995, p. 33, 226), Mikhailov foi o grande teórico da Documentação e a origem conceitual da Informatika relaciona-se claramente com o movimento de informação científica institucionalizado por Otlet e La Fontaine e com o amplo espectro dos problemas gerais da ciência.

Devido ao vigor pragmático e poderio econômico que possibilitou o predomínio posterior da corrente estadunidense, e após a queda do Muro de Berlim, a corrente soviética perdeu seu ritmo inicial de desenvolvimento (MOREIRO GONZÁLEZ, 1995). Contudo, supomos que a influência soviética permaneça de algum modo nos países de histórico socialista, como no caso da obra em que nos baseamos, publicada em Cuba, em 1973.

\subsection{Corrente alemã}

Segundo López Yepes (1995, p. 197-214), a abordagem documentalista alemã surgiu no final da década de 1960, um pouco depois do surgimento da linha estadunidense, como reação a uma tradução para o alemão do trabalho de Harold Borko. Permaneceram duas correntes na Alemanha: uma anglo-saxã e outra autóctone denominada Ciência da Informação e Documentação (Information-und Dokumentationwissenschaft), influenciada pelas doutrinas da antiga União Soviética.

O maior impulsionador da segunda linha citada é Josef Koblitz, da Universidade de Berlim, onde esta disciplina foi instaurada. A sedimentação desta abordagem ocorreu entre 1969 e 1975, sendo definida como disciplina pertencente à esfera da informação social organizada, com o duplo objetivo de proporcionar informação aos usuários e estudar os métodos de produção, armazenamento, recuperação e disseminação de informação documentária, os quais se configuram como as quatro fases do processo documentário. Segundo Koblitz, o termo Documentação era insuficiente para designar uma área completa de informação especializada, motivo pelo qual foi acrescentado o termo Informação, como inicialmente fez Otlet em 1905 (mas cuja distinção conceitual foi questionada um século depois, como apontamos em relato sobre reflexões realizadas em Portugal). 


\section{As configurações da Documentação no Brasil}

Os princípios documentários em geral e a obra de Otlet são conhecidos no Brasil principalmente por meio da CDU. Assim como em outros países da América Latina, houve influência do IIB no período que correspondeu ao início de suas atividades, como segue.

Segundo o engenheiro paulista Victor da Silva Freire (1901), até 1899, o IIB tinha como membro brasileiro apenas Juliano Moreira, diretor dos Annais da Sociedade de Medicina e Cirurgia da Bahia. Freire publicou um estudo sobre a CDU no Annuario da Escola Polytechnica de São Paulo, onde salientava a necessidade da participação do Brasil na organização internacional da bibliografia científica. Este estudo foi publicado pelo IIB, no qual consta a informação de que a Livraria Civilização, em São Paulo, recebia assinaturas e encomendas de publicações do IIB e fornecia equipamentos e móveis por ele adotados. Segundo Fonseca (1961, p. 270-271), em 1900, Oswaldo Cruz introduziu a CDU na biblioteca do instituto de pesquisas que fundou e hoje tem o seu nome, mas acredita que foi Manoel Cícero Peregrino da Silva, diretor-geral da Biblioteca Nacional, no Rio de Janeiro, de 1900 a 1915 e de 1919 a 1921, o responsável pela dinamização das atividades bibliográficas e pela influência da Documentação no país. Nesta instituição, ele criou o primeiro curso de Biblioteconomia na América Latina em 1911 e o Serviço de Bibliografia e Documentação em correspondência com o IIB, no mesmo ano, com a pretensão de organizar o repertório bibliográfico brasileiro em fichas catalográficas e com uso da CDU, incluindo o tratamento dos artigos de periódicos, como uma contribuição ao controle bibliográfico internacional. A despeito destes esforços, Fonseca (1961, p. 271) afirma que "é pena que os sucessores imediatos de Manoel Cícero Peregrino da Silva não tenham se interessado por êsse órgão, no qual foram previstas quase tôdas as peças dos modernos centros de documentação".

O esfriamento que se seguiu quanto à influência europeia foi rompido apenas com a criação do Instituto Brasileiro de Bibliografia e Documentação (IBBD) ${ }^{4}$, em 1954, como decorrência da atuação de Lydia de Queiróz Sambaquy que o idealizou e presidiu. Foi então implementada uma abordagem informacional do trabalho bibliográfico, elaborado pelo abandono de uma certa Biblioteconomia 'pura' para uma composição com base no conceito da Documentação, mais propriamente da informação científica (ODDONE, 2006, p. 50). Para entender esta atuação de Sambaquy, Oddone (2004) retorna à renovação das técnicas da Biblioteconomia brasileira na década de 1940, explorando o papel desempenhado por esta bibliotecária, no âmbito do Departamento Administrativo do Serviço Público (DASP) à frente do Sistema de Intercâmbio de Catalogação (SIC), quando a ideia do trabalho cooperativo e em rede foi defendida e implementada. Mais tarde, Lydia Sambaquy, Edson Nery da Fonseca e outros profissionais do IBBD aprofundaram seus conhecimentos sobre a FID e a Documentação e, em termos nacionais,

\footnotetext{
${ }^{4}$ O IBBD foi transformado no Instituto Brasileiro de Informação em Ciência e Tecnologia (IBICT) em 1976.
} 
resgataram as 'aventuras' de Manoel Cícero Peregrino da Silva no 'reino da documentação' no início do século XX, como forma considerada mais interessante de construir o projeto em andamento que a de iniciar um novo arcabouço teórico-discursivo.

Posteriormente, Zaher e Gomes produziram cursos e textos (ZAHER ; GOMES, 1972, ZAHER, 1968 e 1974) que demonstram a atuação do IBBD quanto à abordagem de Documentação adotada e ao caminho para a Ciência da Informação que se configurava. Quanto à produção de literatura, ressaltamos a tese de livre-docência defendida por Hagar Espanha Gomes (GOMES, 1975) sobre o pensamento de Paul Otlet e os princípios do UNISIST (United Nations Information System in Science and Technology) em 1975, período em que autores chave da retomada da concepção otletiana de Documentação - como López Yepes e Rayward estavam iniciando seus trabalhos.

Segundo Oddone (2006, p. 52), as atividades exercidas pelo IBBD referiam-se a um domínio híbrido do saber, situado a meio caminho entre Biblioteconomia e Documentação, para o qual ainda não havia uma designação apropriada. Foi neste contexto que o Brasil partiu para o alinhamento dos postulados da Ciência da Informação da corrente estadunidense.

Em função desta herança estadunidense, a Documentação é muitas vezes: relacionada às atividades de microfilmagem; entendida como Biblioteconomia Especializada (como se evidencia pelos termos documentação médica, documentação agrícola etc.); ou abordada segundo o tipo de documento tratado (documentação audiovisual, fotográfica, fílmica etc.). Dias (2000) discorre sobre os termos Biblioteconomia, Documentação e Ciência da Informação apontando os usos e desusos do termo Documentação no Brasil, hoje em geral atrelado à Biblioteconomia Especializada nas diversas áreas do conhecimento. Este autor questiona a necessidade de termos próprios - como Documentação e documentalistas - para indicar práticas bibliotecárias de promoção de acesso à informação. Considerando a pertinência desta observação, uma vez que a dispersão profissional não foi fator de avanço, ressaltamos a necessidade do conhecimento de nossa história, para que novas rupturas não sejam continuamente realizadas.

Exceção efetiva à vertente estadunidense é aquela construída pelo Grupo Temma, da Escola de Comunicações e Artes (ECA), da Universidade de São Paulo (USP), a partir dos anos 1980, sobre área então denominada Análise Documentária. Este Grupo, preocupado com a necessidade de cientifização dos processos e instrumentos de organização da informação, buscou inicialmente na Linguística (segundo estudos de Gardin), e posteriormente na Semiótica, na Lógica, na Comunicação e na Terminologia, os aportes teóricos para o aprofundamento dos processos citados. As pesquisas resultantes deflagram menos uma dimensão global da Documentação que uma perspectiva conceitual (e, como decorrência, histórica) da organização da informação e seu papel na produção e uso do conhecimento registrado. Escolas como a da UNESP de Marília têm 
construído sua produção científica a partir destas reflexões e da literatura europeia, em especial, a espanhola. Há uma extensa produção científica realizada por esta linha de pesquisa da USP; recentemente a dissertação de Santos (2006) tratou especialmente das origens da Documentação e da noção de princípio monográfico.

Deste modo, a história da Documentação no Brasil poderia ser descrita por ao menos três momentos: no início do século $X X$, por envolvimento com o projeto do IIB; a partir dos anos 1940, em movimento que levou à criação do IBBD em 1954 até a introdução da corrente estadunidense de Ciência da Informação no Brasil; e a partir dos anos 1980, com o início dos estudos do Grupo Temma, da ECA/USP. É possível ainda traçar um paralelo entre estes três momentos da Documentação no Brasil e o ensino na área até o início das atividades de pesquisa, como segue. As influências europeias trazidas ao Brasil pelo curso de formação de profissionais da Biblioteca Nacional em 1911 momento em que houve grande afinidade com os propósitos do IIB -, logo foram suplantadas pela abordagem pragmática de origem estadunidense dos cursos paulistas desde os anos 1930 (a partir dos quais surgiram muitos dos cursos do país). Somente nos anos 1950 e 1960 insumos europeus retornaram ao país por meio da absorção de algumas técnicas e instrumentos da Documentação - como a CDU e o catálogo sistemático - nos currículos e nas práticas profissionais, provavelmente influenciados pelos cursos de especialização de Documentação Científica promovidos pelo IBBD (CASTRO, 2000, FONSECA, 1969, e ODDONE, 2004 e 2006). A partir daí as palavras Biblioteconomia e Documentação começaram a ser utilizadas, juntas ou separadas. Nos anos 1970, com a instauração do curso de mestrado do IBBD, e em especial nos anos 1990, quando cursos em nível de doutorado tiveram início, a denominação Ciência da Informação passou a ser mais amplamente adotada, ainda que com certa falta de clareza sobre sua significação e baixa capilaridade entre a comunidade profissional. Quanto à pesquisa realizada pelo Grupo Temma desde os anos 1980, seus resultados são pouco conhecidos no país.

Retomando a configuração dos países pioneiros no tema, observamos que a Documentação produzida nos Estados Unidos nos anos 1950 acabou por focar-se no processamento mecânico da informação, enquanto obras documentárias de origem europeia e soviética, produzidas a partir dos anos 1960, são mais abrangentes. Autores como Gardin (1966, 1973), Coyaud (1966), Van Dijk (1964), Chaumier (1971) e os russos Chernyi, Gilyarevskii e Mikhailov (1973) abordam as linguagens documentárias em seus fundamentos, apresentando suas características estruturais e funcionais com base em aportes linguísticos, e discorrem sobre os recursos tecnológicos relacionados. Já a pesquisa produzida na Inglaterra interessa à medida que deflagra as abordagens europeia e estadunidense, como demonstra obra que trata dos métodos mecânicos para tratamento e recuperação da informação, mas reconhece a unicidade 
do problema da recuperação frente aos métodos tradicionais como abordagens distintas que começavam a convergir (VICKERY, 1962).

Deste modo, se o Brasil caminhou rumo à constituição de abordagem de Ciência da Informação preconizada nos Estados Unidos, suspeitamos que já recebia influência anterior do movimento da Documentação deste país. Portanto, a influência da Documentação europeia sobre o Brasil ocorrida do final do século XIX aos anos 1930, mesmo que pontual, foi efetiva. Já a retomada da Documentação a partir dos anos 1950 contou simultaneamente com insumos europeus e estadunidenses, mais propriamente estes últimos. Na esteira dos Estados Unidos e passado o auge da Documentação europeia, esta não encontrou eco no Brasil. Outros países da América Latina, contudo, muito provavelmente por influência do idioma espanhol, realizaram outro tipo de absorção da Documentação, menos fiel à ideologia estadunidense, e ainda hoje presente na literatura e práticas profissionais que realizam.

\section{Considerações Finais}

Ainda que a proposta otletiana implicasse em colaboração e não em dispersão de suas atividades, assim como em fundamentos teóricos comuns e não em áreas distintas ou concorrentes, a Documentação não pode ser entendida sem a exploração da construção de sua relação controversa com a Biblioteconomia. Muitas passagens da história estadunidense e europeia apresentada apontam para esta relação que se deu inicialmente quando foi enunciada a necessidade de novos procedimentos que atendessem às demandas de acesso à informação, cuja produção passou a crescer e a se diversificar sistematicamente. A Documentação foi proposta na Bélgica, mas sedimentada na França, como processo geral para disponibilizar o conteúdo dos diversos documentos, que as atividades de gestão de acervos efetivadas então pela Biblioteconomia contribuíam para realizar. Contudo, desenvolveu-se com foco na informação técnica e científica, deixando a parte e com outro grupo a atenção para as atividades de promoção da leitura. A Documentação manifestou-se décadas depois nos Estados Unidos onde foi rapidamente substituída pela Biblioteconomia Especializada e, em seguida, pela área conhecida como Information Retrieval. Daí, surgiu a corrente dominante da Ciência da Informação. Estas distinções demonstram as particularidades desta área do conhecimento e profissões relacionadas nestes dois países de influência.

A Documentação, marcadamente europeia, foi esquecida entre os anos 1930 e 1950, enquanto a corrente estadunidense da Ciência da Informação surgida nos anos 1960 tem presença em praticamente todo o mundo. O apagamento da Documentação nestes 20 anos é tema ainda por ser explorado já que, embora tenha perdido a abrangência da proposta inicial, em muitas correntes europeias preservou substancialmente a capacidade de sustentar teórica e metodologicamente 
o trato com a informação bibliográfica, arquivística e museológica por meio do que podemos chamar de processos documentários.

Se especialmente na França as distinções entre Biblioteconomia e Documentação são claras, no Brasil, esta dicotomia é vaga, assim como a dicotomia que se seguiu, a da Biblioteconomia versus Ciência da Informação. O estudo da influência dos movimentos da Documentação e da Ciência da Informação que ocorreram nos Estados Unidos pode levar a maior entendimento destas relações no Brasil. Quanto à Documentação europeia, profissionais e pesquisadores formados nas escolas brasileiras citadas anteriormente, desenvolvem seus trabalhos nesta abordagem, em especial quanto aos processos de organização da informação. No entanto, a dimensão da proposta de Otlet, dos primeiros documentalistas e dos teóricos franceses, espanhóis e portugueses que os precederam, ainda está por ser mais amplamente disseminada e refletida no país.

Deste modo, a hipótese de que a compreensão sobre a história da Ciência da Informação no Brasil seria dependente da exploração do movimento da Documentação brasileira - de origem europeia e estadunidense -, de modo a conhecer como o país realizou a confrontação e articulação com o que se conhecia até então como Biblioteconomia e como veio posteriormente a incorporar a linha estadunidense de Ciência da Informação, pode ser confirmada parcialmente, já que esta exploração inicial mostrou-se pertinente, embora estudos mais aprofundados sejam necessários.

A pesquisa evidencia a forte herança da Documentação na França, Espanha e Portugal e a validade desta corrente para a superação das abordagens restritivas atribuídas à Biblioteconomia e dos contínuos embates sobre o objeto da Ciência da Informação.

\section{Referências}

ARNAU RIVED, P.; SAGREDO FERNÁNDEZ, F. Ante la traducción del libro de W. B. Rayward. Documentación de las Ciencias de la Información, v. 16, p. 107-113, 1993. Trad. do prológo de Rayward da edição em espanhol de seu livro publicado em 1975, em Moscou.

BRADFORD, S. C. Documentation. London: Crosley Lockwood, 1951.

BRIET, S. Qu'est-ce que la documentation? Paris: Édit, 1951. Disponível em:

$<$ http://martinetl.free.fr/suzannebriet/questcequeladocumentation/briet.p df>. Acesso em: 22 ago. 2009.

BRIET, S. What is documentation? Lanham: Scarecrow, 2006. Trad. de: Qu'est-ce que la documentation? Paris: Édit, 1951.

BUCKLAND, M. Le centenaire de "Madame Documentation": Suzanne Briet, 1894-1989. Documentaliste-Sciences de I'Information, v. 32, n. 3, p. 179-181, 1995. Também publicado em: JASIS, v. 46, n. 3, p. 235-237, Apr. 1995. 
BUCKLAND, M. Documentation, Information Science and Library Science in the USA. Information Processing \& Management, v. 32, n. 1, p. 63-76, 1996.

CASTRO, C. A. História da Biblioteconomia brasileira: perspectiva histórica. Brasília: Thesaurus, 2000.

CHAUMIER, J. Les techniques documentaires. Paris: Presses Universitaires de France, 1971. (Que sais-je?, 1419).

CHERNYI, A. I. ; GILYAREVSKII, R. S. ; MIKHAILOV, A. I. Fundamentos de la informática. La Habana: IDICT/Academia de Ciencias de Cuba, 1973. 2 v. Trad. de: Osnovi Informatiki. Moscú: Nauka, 1968.

COUZINET, V. Olhar crítico sobre as Ciências da Informação na França. In: WORKSHOP EM CIÊNCIA DA INFORMAÇÃO, 11 e 12 nov. 2004, Niterói. Anais... Niterói: ANCIB ; UFF, 2004.

COUZINET, V. ; RÉGIMBEAU, G. ; COURBIÈRES, C. Sur le document: notion, travaux et propositions. In: COUZINET, V. ; RAUZIER, J.-M. (Col.). Jean Meyriat, théoricien et praticien de l'information-documentation. Paris: ADBS Éditions, 2001. p. 467-506.

COYAUD, M. Introduction à l'étude des langages documentaires. Paris: Klincksieck, 1966.

CURRÁS, E. Las ciencias de la documentación: bibliotecología, archivología, documentación e información. Barcelona: Mitre, 1982.

DIAS, E. W. Biblioteconomia e ciência da informação: natureza e relações. Perspectivas em Ciência da Informação, Belo Horizonte, v. 5, n. esp., p. 67-80, 2000.

FAYET-SCRIBE, S. Histoire de la documentation en France: culture, science et technologie de l'information, 1895-1937. Paris: CNRS Editions, 2001. (CNRS Histoire).

FONSECA, E. N. da. A Classificação Decimal Universal no Brasil. In: BRADFORD, S. C. Documentação. Rio de Janeiro: Fundo de Cultura, 1961. 292 p. (Biblioteca Fundo Universal de Cultura : Estante de Documentação). p. 269-278. Trad. de: Documentation. London: Crosby Lockwood, 1953.

FONSECA, E. N. da. Prefácio da edição brasileira. In: SHERA, J. ; EGAN, M. Catálogo sistemático: princípios básicos e utilização. Brasília: Editora Universidade de Brasília, 1969. (Biblioteconomia e Documentação, 1). p. ix-x. Trad. de: The classified catalog: basic principles and practices. Chicago: ALA, 1956.

FREIRE, V. da S. A Bibliographia Universal e a Classificação Decimal: subsídio para a participação do Brasil na organisação internacional da bibliographia scientifica. São Paulo: Typographia Brazil de Carlos Gerke \& Cia., 1901. (Do "Annuario da Escola Polytechnica de São Paulo"). 
GARDIN, J.-C. Elements d'un modele pour la description des lexiques documentaires. Bulletin des Bibliothèques de France, n. 5, p. 171-182, 1966.

GARDIN, J.-C. Document analysis and linguistic theory. Journal of Documentation, v. 29, p. 2, p. 137-168, 1973.

GOMES, H. E. O pensamento de Paul Otlet e os princípios do UNISIST. Tese (Livre-Docência) - Universidade Federal Fluminense (UFF), Niterói, 1975.

LÓPEZ-CÓZAR, E. D. La investigación en biblioteconomía y documentación. Gijón: Trea, 2002. (Biblioteconomía y Administración Cultural, 61).

LÓPEZ YEPES, J. Teoría de la Documentación. Pamplona: EUNSA, 1978.

LÓPEZ YEPES, J. La Documentación como disciplina: teoría e historia. 2. ed. Pamplona: EUNSA, 1995.

MEYRIAT, J. Un siècle de documentation: la chose et le mot. Documentaliste-Sciences de I'Information, v. 30, n. 4-5, p. 192-198, 1993.

MOREIRO GONZÁLEZ, J. A. Qué fue del concepto soviético "Informatika"? Documentación de las Ciencias de la Información, Madrid, n. 18, p. 173182, 1995.

ODDONE, N. Ciência da Informação em perspectiva histórica: Lydia de Queiroz Sambaquy e o aporte da Documentação (Brasil, 1930-1970). Tese (Doutorado) - Escola de Comunicação/IBICT-UFRJ, Rio de Janeiro, 2004.

ODDONE, N. O IBBD e a informação científica: uma perspectiva histórica para a ciência da informação no Brasil. Ciência da Informação, v. 35, n. 1, p. 45-56, 2006.

ORTEGA, C. D. Relações históricas entre Biblioteconomia, Documentação e Ciência da Informação. DataGramaZero: Revista de Ciência da Informação, Rio de Janeiro, v. 5, n. 5, p. 3, 2004. Disponível em: <http://www.dgz.org.br/out04/F_I_art.htm>. Acesso em: 22 ago. 2009.

OTLET, P. Documentos e Documentação. Trad. de Hagar Espanha. Paris, 1937. Introdução aos trabalhos do Congresso Mundial da Documentação Universal, realizado em Paris, em 1937. Disponível em: <http://www.conexaorio.com/biti/otlet/index.htm>. Acesso em: 22 ago. 2009.

OTLET, P. El Tratado de Documentación: el libro sobre el libro: teoría y práctica. Murcia: Universidad de Murcia, 1996. Trad. de: Traité de Documentation: le livre sur le livre: théorie et pratique. Bruxelles: Mundaneum, 1934. Versão original disponível em: <http://lib.ugent.be/fulltxt/handle/1854/5612/Traite_de_documentation_ ocr.pdf>. Acesso em: 22 ago. 2009.

RAYWARD, W. B. The UDC and FID: a historical perspective. The Library Quaterly, n. 37, p. 259-278, 1967. 
RAYWARD, W. B. The universe of information. The work of Paul Otlet for Documentation and International Organisation. Moscow: VINITI, 1975.

RIBEIRO, F. Desfazer equívocos: Ciência ou Ciências da Informação? Newsletter "A Informação", n. 1, p. 19-22, 2005. Disponível em: <http://www.a-informacao.blogspot.com>. Acesso em: 22 ago. 2009.

SAGREDO FERNÁNDEZ, F. ; IZQUIERDO ARROYO, J. M. Concepción lógicolingüística de la Documentación. Madrid: IBERCOM, 1983.

SANTOS, P. de M. L. Ponto de inflexão Otlet: uma visão sobre as origens da Documentação e o processo de construção do Princípio Monográfico. Dissertação (Mestrado) - Escola de Comunicações e Artes/USP, São Paulo, 2006.

SHERA, J. Documentation and the organization of knowledge. London: Crosley Lockwood, 1966.

; EGAN, M. Exame do estado atual da biblioteconomia e documentação. In: BRADFORD, S. C. Documentação. Rio de Janeiro: Fundo de Cultura, 1961. 292 p. (Biblioteca Fundo Universal de Cultura : Estante de Documentação). p. 15-61. Trad. de: Documentation. London: Crosby Lockwood, 1953.

SILVA, A. M. da ; RIBEIRO, F. Das "Ciências" Documentais à Ciência da Informação: ensaio epistemológico para um novo modelo curricular. Porto: Afrontamento, 2002.

VAN DIJK, M. Enregistrement et recherche de l'information documentaire. Bruxelas: Presses Universitaires, 1964.

VICKERY, B. C. Classification and indexing in science. London: Butterworths, 1959.

VICKERY, B. C. Techniques modernes de Documentation: analyse des systèmes de recherche de documents. Paris: Dunod, 1962. (Sigma). Trad. de: On retrieval system theory. Londres: Butterwoth, 1962.

WOLEDGE, G. Bibliography and Documentation: words and ideas. Journal of Documentation, v. 39, n. 4, p. 266-279, 1983.

ZAHER, C. R. ; GOMES, H. E. Da bibliografia à ciência da informação: um histórico e uma posição. Ciência da Informação, Rio de Janeiro, v. 1, n. 1, p. 5-7, 1972.

ZAHER, C. R. Introdução à Documentação. 2. ed. rev. Rio de Janeiro, 1968.

ZAHER, C. R. Da documentação à informática. In: SEMINÁRIO DA DOCUMENTAÇÃO À INFORMÁTICA, 1971, Rio de Janeiro. Anais... Rio de Janeiro: FGV, 1974. p. 49-86. 